\title{
Practice Variations in the Diagnosis, Monitoring, and Treatment of Systemic Lupus Erythematosus in Canada
}

\author{
Stephanie O. Keeling, Asvina Bissonauth, Sasha Bernatsky, Ben Vandermeer, Paul R. Fortin, \\ Dafna D. Gladman, Christine Peschken, and Murray B. Urowitz
}

ABSTRACT. Objective. To evaluate the diagnosis, monitoring, and treatment of systemic lupus erythematosus (SLE) in Canada.

Methods. A 63-question electronic survey was developed with the Canadian Rheumatology Association and others. Descriptive analyses of responses were performed.

Results. Survey respondents $(\mathrm{n}=175)$ reported varying practices in the diagnosis, monitoring, and treatment of SLE. Performance of laboratory investigations for diagnosis and monitoring varied, with $78 \%$ of responders performing them at least every 6 months. Validated measures of SLE disease activity and damage were not commonly used. Most common first-line agents besides steroids for induction therapy for class III or IV lupus nephritis included intravenous cyclophosphamide and mycophenolate mofetil. Antimalarial use was common, with $96 \%$ of respondents using these in active skin disease. Over $60 \%$ of respondents indicated that $80-100 \%$ of their patients were taking antimalarials, while another $25 \%$ indicated they used these drugs in up to $80 \%$ of their patients. There were $71 \%$ of responders who reported completing frequent (6-12 mos) ophthalmology screening in patients taking antimalarials. Biologics were infrequently used. Responders were more likely to stop azathioprine and chloroquine than hydroxychloroquine in pregnant patients with SLE. Other aspects of routine care including vaccination and cardiovascular risk management varied considerably. The majority $(80 \%)$ agreed that a dedicated multidisciplinary care team would improve SLE care.

Conclusion. Considerable practice variation in SLE management was noted. This may help inform future recommendations for the diagnosis, monitoring, and treatment of SLE in Canada. (First Release August 1 2018; J Rheumatol 2018;45:1440-7; doi:10.3899/jrheum.171307)

Key Indexing Terms:

SYSTEMIC LUPUS ERYTHEMATOSUS

DISEASE ACTIVITY DIAGNOSIS

\section{PHYSICIAN PRACTICE PATTERNS MONITORING TREATMENT}

From the Division of Rheumatology, University of Alberta, Edmonton, Alberta; Division of Rheumatology, McGill University, Montreal, Quebec; Alberta Research Centre for Health Evidence, Department of Pediatrics, University of Alberta, Edmonton, Alberta; Division of Rheumatology, CHU de Québec, Université Laval, Quebec City, Quebec; Division of Rheumatology, University of Toronto, Toronto, Ontario; Division of Rheumatology, University of Manitoba, Winnipeg, Manitoba, Canada. Grant support from the Canadian Institute of Health Research, Canadian Rheumatology Association, and Lupus Canada. Dr. Fortin holds a tier 1 Canada Research Chair on Systemic Autoimmune Rheumatic Diseases.

S.O. Keeling, MD, MSc, FRCP $(C)$, Division of Rheumatology, University of Alberta; A. Bissonauth, MRes, Research Coordinator, Division of Rheumatology, University of Alberta; S. Bernatsky, MD, PhD, FRCPC, Professor of Medicine, Division of Rheumatology, McGill University; $B$. Vandermeer, MSc, Biostatistician, Alberta Research Centre for Health Evidence, Department of Pediatrics, University of Alberta; P.R. Fortin, $M D, F R C P C$, Professor of Medicine, Division of Rheumatology, CHU de Québec, Université Laval; D.D. Gladman, MD, FRCPC, Professor of Medicine, Division of Rheumatology, University of Toronto; C. Peschken, MD, FRCPC, Associate Professor of Medicine, Division of Rheumatology, University of Manitoba; M.B. Urowitz, MD, FRCPC, Division of Rheumatology, University of Toronto.

Address correspondence to Dr. S.O. Keeling, 8-129 Clinical Sciences Building, University of Alberta, Edmonton, Alberta T6G 2G3, Canada. E-mail: Stephanie.keeling@ualberta.ca

Full Release Article. For details see Reprints and Permissions at jrheum.org

Accepted for publication May 10, 2018.
Systemic lupus erythematosus (SLE) can be a challenging disease to diagnose, monitor, and treat, leading many international organizations [European League Against Rheumatism, American College of Rheumatology (ACR)] to develop guidelines on various aspects of its management ${ }^{1,2,3,4,5,6}$.

In Canada, the prevalence of SLE is about 1 in 2000 individuals $\mathrm{s}^{7,8}$, translating to over 16,000 patients, representing a significant disease burden. Primary care physicians (family doctors) provide first-line care for the majority of Canadians. In this universal healthcare system, patients suspected of having SLE are referred by the primary care physician to a specialist, the specialty type depending on several factors including degree of organ involvement, geography, and specialist accessibility. Rheumatologists are largely viewed as the main specialists involved in SLE care, with the exception of patients with isolated organ involvement (e.g., nephritis, cutaneous disease). Rheumatologist distribution in Canada varies between academic centers with dedicated SLE clinics to community rheumatologists. Another important consideration is medication coverage, which varies interprovincially, thereby affecting treatment choices for patients.

Personal non-commercial use only. The Journal of Rheumatology Copyright $\odot$ $)$ 2018. All rights reserved 
Defining best practices for the most effective monitoring and treatment of SLE can thus be challenging. SLE outcomes are influenced by multiple factors, including the degree of disease activity and damage, socioeconomic status, and geographical variability in care provision ${ }^{8}$. Recommendations targeted to the SLE healthcare provider for the diagnosis, monitoring, and pharmacotherapy of SLE in Canada are currently nonexistent; however, their development may help address these issues and address existing gaps in SLE management.

The aims of our study were to evaluate existing practice patterns in the diagnosis, monitoring, and treatment of patients with SLE in Canada, to identify the focus of future Canadian SLE recommendations based on those of the Grading of Recommendations Assessment, Development, and Evaluation (GRADE) working group.

\section{MATERIALS AND METHODS}

A questionnaire to evaluate the practice patterns in the diagnosis, monitoring, and treatment of SLE was developed and tested by a consortium including 2 members of the Canadian Rheumatology Association (CRA) therapeutics subcommittee, 12 members of the Canadian Network for Improved Outcomes in Systematic Lupus Erythematosus (CaNIOS), and 2 other Canadian experts in SLE care. After pilot testing $(n=16)$, the resulting 63-question (English/French) electronic survey (Survey Monkey) was distributed to the CRA membership in November 2012 by e-mail link (Supplementary Data 1, available with the online version of this article). The CRA membership ( $\mathrm{n}=494$ rheumatologists in 2012) includes both academic and community rheumatologists caring for both adult and pediatric populations. Responses varied between sections of the survey; some chose to skip certain questions or provide open-ended answers in a text box. Responses are therefore reported as "percentage of responders" in the results text with the number (n) of responders reported in the tables per section. Responders were given the option to skip the pregnancy section if they felt it was not applicable to their practice. The Cochrane-Armitage trend test was used to compare differences across the ordinal responses between academic and nonacademic/community rheumatologists for the performance of various disease indices and laboratory studies. Fisher's exact tests were used to compare differences between academic and nonacademic/community rheumatologists for binary responses of interest, including (1) percent taking longterm glucocorticoids, (2) percentage of patients taking antimalarials, (3) discontinuation of antimalarials, and (4) use of electronic medical records (EMR) to evaluate patients with SLE (data not shown).

Results using descriptive statistics were presented and discussed by members of a newly formed Canadian SLE Working Group (Supplementary Data 2, available with the online version of this article) at a meeting in February 2013 to help identify areas of practice variation with a longterm goal of informing the development of GRADE-based Canadian recommendations for the diagnosis, monitoring, and pharmacotherapy of SLE. Ethics approval through the University of Alberta was granted for this study (PrO 34720).

\section{RESULTS}

Demographics. Of 496 surveys circulated, 175 CRA rheumatology and CaNIOS members responded (response rate $=$ $35 \%)$. They were mostly female (88\%) and the majority (41\%) from Ontario, reflecting the national distribution of specialty care. Responders were primarily adult rheumatologists $(85 \%)$, pediatric rheumatologists $(10 \%)$, and general internists (3\%). The majority (66\%) practiced at academic/ teaching centers, $42 \%$ had a dedicated SLE clinic, and $62 \%$ did not report systematic collection of SLE-related outcome measures. There were 147 respondents to questions on diagnosis, monitoring, and treatment of renal and non-renal SLE, while 129 responded to the SLE pregnancy questions. Evaluation of SLE. The clinical manifestations of SLE reported as most commonly seen by responders were musculoskeletal ones $(41 \%)$, followed by mucocutaneous $(26 \%)$, and fatigue (24\%; Table 1). The data represented should not be considered an estimate of prevalence of different manifestations, but rather the percent of respondents who ranked specific manifestations as most common.

The most commonly used laboratory investigations by responders for the initial and subsequent patient visit was complete blood count (100\%), followed by renal indices (urinalyses and serum creatinine) and complement levels (Table 1). Thirty-nine percent of responders reported using the modified ACR 1997 classification criteria ${ }^{9,10}$. Of all possible disease activity and damage measures, the swollen joint count was most often reported as being completed (by $77 \%$ of responders), while $<50 \%$ reported using established SLE disease activity indices (e.g., SLE Disease Activity Index ${ }^{11}$, used by $16 \%$ of respondents) or damage measures [e.g., SLE International Collaborating Clinics (SLICC)/ACR Damage Index ${ }^{12}$ ). Thirty-nine percent of responders reported ordering laboratory tests to measure SLE activity every 6 months in a stable patient (i.e., patients with minimal/no active disease for at least $1 \mathrm{yr}$ ), while $35 \%$ reviewed such patients at 3-month to 4 -month intervals and $11 \%$ every $1-3$ months.

A comparison between academic and nonacademic rheumatologists (Table 2) confirmed a statistically significant difference in the use of the SLICC/ACR Damage Index score and the use of antinuclear antibody (ANA) and extractable nuclear antigen in the ongoing assessment of patients with SLE.

Pharmacotherapy of SLE nephritis. The majority (88\%) reported that nephritis was treated most commonly by nephrologists, followed by rheumatologists (60\%; Table 3); those responses could have included co-management. In addition to steroids, $50 \%$ of responders used intravenous cyclophosphamide (CYC) as first-line therapy for the induction of class III or IV nephritis, while 39\% used mycophenolate mofetil (MMF) first for nephritis induction therapy. Other drugs used as induction therapy included azathioprine (AZA), oral CYC, and rituximab (RTX; Table $3)$. In the case of failure of induction therapy for lupus nephritis with intravenous CYC, the most common second choice was MMF (33\%; Table 3).

Pharmacotherapy of non-renal SLE $(n=147)$. The most commonly used medication by responders for the treatment of non-renal SLE was hydroxychloroquine (HCQ; 99\%). Over $60 \%$ of respondents indicated that $80-100 \%$ of their patients were taking these drugs, while another $25 \%$

$$
\text { Personal non-commercial use only. The Journal of Rheumatology Copyright @ } 2018 \text {. All rights reserved. }
$$


Table 1. The diagnosis and monitoring of SLE in clinic ( $\mathrm{n}=155$ responders).

\begin{tabular}{|c|c|c|}
\hline Questionnaire Items & Mode (\% responders) & Strategies (\% responders) \\
\hline Use revised ACR 1997 criteria for diagnosis & Usually (39) & Always (35), sometimes (15), never (10) \\
\hline $\begin{array}{l}\text { Ranking of most common organ manifestations } \\
\text { of SLE in clinical practice }\end{array}$ & Musculoskeletal (41) & Mucocutaneous (26), fatigue (24), renal (6), fibromyalgia (4) \\
\hline Laboratory investigations for initial patient visit & $\mathrm{CBC}(100)$ & $\begin{array}{l}\text { > 75\% responders: creatinine (99), urinalysis (99), WBC and } \\
\text { differential (98), dsDNA (96), ANA (96), antibodies against } \\
\text { extractable nuclear antigens (95), complement (C3/C4 or } \\
\text { functional assay; 94), liver enzymes (91), CRP (86), ESR ( } 84) \\
11-74 \% \text { responders: anticardiolipin/antiphospholipid antibodies } \\
\text { (64), LAC/inhibitor (58), INR/PTT (49), urine protein:creatinine } \\
\text { ratio ( } 47 \text { ), hepatitis B/C (39), quantitative immunoglobulins } \\
\text { (35), anti- } \beta_{2} \text {-GPI (22), CH50 or CH100 (15), other (17) } \\
\leq 10 \% \text { responders: } 24 \text {-h urine protein (9), ANCA (8), 24-h urine } \\
\text { creatinine (7), HIV (5) }\end{array}$ \\
\hline $\begin{array}{l}\text { Tests always used to evaluate disease activity, } \\
\text { damage, or comorbidity on a regular basis }\end{array}$ & Swollen joint count (77) & $\begin{array}{l}50-75 \% \text { responders: tender joint count (70), BMD (56) } \\
11-50 \% \text { responders: PGA (42), PtGA (31), SLEDAI (any } \\
\text { version; 16), other (14), SLICC/ACR Damage Index (12) } \\
\leq 10 \% \text { responders: SLAM (2), BILAG (any version; 1), } \\
\text { Charlson Comorbidity Index (1) }\end{array}$ \\
\hline Tests used to monitor disease activity over time & $\mathrm{CBC}(98)$ & $\begin{array}{l}\text { 75-98\% responders: creatinine (97), WBC differential (95), } \\
\text { urinalysis (94), complement C3, C4 or functional assay ( } 82) \text {; } \\
\text { 50-75\% responders: CRP ( } 75) \text {, ESR (72), dsDNA ( } 72) \text {, liver } \\
\text { enzymes (59); 10-50\% responders: urine protein: creatinine ratio } \\
\text { (44), ANA (18), antibodies against nuclear antigens (17), 24-h } \\
\text { urine protein (14), anticardiolipin/antiphospholipid antibodies } \\
\text { (14), INR/PTT (11); } \leq 10 \% \text { : LAC/inhibitor (10), quantitative } \\
\text { immunoglobulins (10), other (9), 24-h urine creatinine (8), CH50 } \\
\text { or CH100 (7), anti- } \beta_{2} \text {-GPI (4), ANCA (1), hepatitis B/C (0), HIV (0) }\end{array}$ \\
\hline $\begin{array}{l}\text { Frequency of monitoring disease activity with } \\
\text { laboratory studies in a patient with stable SLE }\end{array}$ & Every 6 months (39) & $\begin{array}{l}\text { Every } 3-4 \text { months }(35) \text {, once a year }(12) \text {, every } 2-3 \text { mos }(10) \text {, } \\
\text { every month (1), no formal laboratory monitoring (1) }\end{array}$ \\
\hline
\end{tabular}

SLE: systemic lupus erythematosus; ACR: American College of Rheumatology; CBC: complete blood count; WBC: white blood cell (count); ANA: antinuclear antibody; CRP: C-reactive protein; ESR: erythrocyte sedimentation rate; LAC: lupus anticoagulant; anti- $\beta_{2}$-GPI: anti- $\beta_{2}$-glycoprotein I; INR/PTT: internationalized normalized ratio/prothrombin time; ANCA: antineutrophil cytoplasmic antibodies; HIV: human immunodeficiency virus; BMD: bone mineral density; PGA: physician's global assessment; PtGA: patient's global assessment; SLEDAI: Systemic Lupus Erythematosus Disease Activity Index; SLICC: Systemic Lupus International Collaborating Clinics; SLAM: Systemic Lupus Activity Measure; BILAG: British Isles Lupus Assessment Group index.

Table 2. Comparison of performance of disease activity, damage, and laboratory indices between academic and nonacademic rheumatologists.

\begin{tabular}{|c|c|c|c|c|c|c|}
\hline \multirow{2}{*}{ Index } & \multirow[t]{2}{*}{ Group } & \multicolumn{4}{|c|}{ Survey Responses, n (\%) } & \multirow[t]{2}{*}{$\mathrm{p}^{*}$} \\
\hline & & Always & Sometimes & Never & Would Like To & \\
\hline SLEDAI, $\mathrm{n}=145$ & Academic, $n=96$ & $24(25)$ & $29(30)$ & $31(32)$ & $12(13)$ & 0.002 \\
\hline \multirow[t]{2}{*}{ BILAG, $\mathrm{n}=150$} & Academic, $\mathrm{n}=101$ & $1(1)$ & $20(20)$ & $70(69)$ & $10(10)$ & 0.02 \\
\hline & Nonacademic, $\mathrm{n}=49$ & $0(0)$ & $3(6)$ & $42(86)$ & $4(8)$ & \\
\hline SLAM, $\mathrm{n}=149$ & Academic, $\mathrm{n}=101$ & $3(3)$ & $16(16)$ & $78(77)$ & $4(4)$ & 0.03 \\
\hline SLICC, $\mathrm{n}=150$ & Nonacademic, $\mathrm{n}=49$ & $0(0)$ & $4(8)$ & $41(84)$ & $4(8)$ & \\
\hline \multirow[t]{2}{*}{ ANA, $n=146$} & Academic, $\mathrm{n}=102$ & $14(14)$ & $27(26)$ & $61(60)$ & $0(0)$ & 0.04 \\
\hline & Nonacademic, $\mathrm{n}=44$ & $12(27)$ & $2(5)$ & $15(34)$ & $15(34)$ & \\
\hline \multirow[t]{2}{*}{$\mathrm{ENA}, \mathrm{n}=152$} & Academic, $\mathrm{n}=104$ & $18(17)$ & $23(22)$ & $62(60)$ & $1(1)$ & 0.01 \\
\hline & Nonacademic, $\mathrm{n}=48$ & $6(13)$ & $31(65)$ & $11(23)$ & $0(0)$ & \\
\hline dsDNA, $n=151$ & Academic, $\mathrm{n}=102$ & $71(71)$ & $29(28)$ & $2(2)$ & $0(0)$ & 1 \\
\hline
\end{tabular}

* Cochran-Armitage trend test. SLEDAI: Systemic Lupus Erythematosus Disease Activity Index; BILAG: British Isles Lupus Assessment Group index; SLAM: Systemic Lupus Activity Measure; SLICC: Systemic Lupus International Collaborating Clinics; ANA: antinuclear antibody; ENA: extractable nuclear antigen. 


\begin{tabular}{|c|c|c|}
\hline Questionnaire Items & Mode (\% responders) & Commonly Repeated Strategies (\% responders) \\
\hline \multicolumn{3}{|l|}{ Renal SLE } \\
\hline Specialist performing routine treatment of nephritis & Nephrologist (88) & Rheumatologist (60), other (6), immunologist (1), general internist (2) \\
\hline $\begin{array}{l}\text { Most common agents used for induction of class } \\
3 \text { or } 4 \text { nephritis* }\end{array}$ & CYC IV (50) & MMF (39), oral CYC (7), AZA (3), RTX (0) \\
\hline $\begin{array}{l}\text { Second-line choice if induction for lupus nephritis } \\
\text { fails, } \mathrm{n}=144\end{array}$ & MMF (33) & $\begin{array}{l}\text { 10-30\% responders: IV methylprednisolone pulse (28), CYC IV (28), } \\
10 \% \text { of responders: RTX (6), oral CYC (3), AZA (3) }\end{array}$ \\
\hline \multicolumn{3}{|l|}{ Non-renal SLE } \\
\hline $\begin{array}{l}\text { Most commonly used medications in the treatment } \\
\text { of non-renal SLE }\end{array}$ & HCQ (99) & 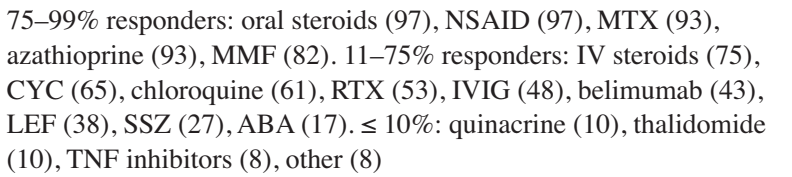 \\
\hline $\begin{array}{l}\text { \% SLE patients taking antimalarials (chloroquine, } \\
\text { HCQ) }\end{array}$ & $81-100 \%$ patients $(67)$ & $61-80 \%(25), 41-60 \%(5), 2140 \%(2), 11-20 \%(1), 0-10 \%(0)$ \\
\hline $\begin{array}{l}\% \text { SLE patients requiring minimum low-dose } \\
\text { prednisone indefinitely }\end{array}$ & $6-10 \%(26)$ & $\begin{array}{l}11-20 \%(24), 41-60 \%(17), 21-40 \%(11), 0-5 \%(11), 61-80 \%(5), \\
81-100 \% \text { (3), have no idea (3) }\end{array}$ \\
\hline $\begin{array}{l}\text { Discontinuation of antimalarials in stable SLE } \\
\text { patients }^{\#}\end{array}$ & No (79) & Yes (16), other (7), I do not know (3) \\
\hline $\begin{array}{l}\text { Adjustment of immunosuppression in stable SLE } \\
\text { patients }^{\dagger}\end{array}$ & Yes (65) & Sometimes (31), no (2), other (1) \\
\hline $\begin{array}{l}\text { Discontinuation of immunosuppression in stable } \\
\text { SLE patients } \ddagger\end{array}$ & $\begin{array}{l}\text { Depends on the extent } \\
\text { of SLE disease/damage } \\
\text { overall (55) }\end{array}$ & $\begin{array}{l}\text { Yes (29), depend on the agent(s) used (26), no (13), I do not } \\
\text { know (4), other (3) }\end{array}$ \\
\hline $\begin{array}{l}\text { Used belimumab in the treatment of patients } \\
\text { with active SLE }\end{array}$ & No (67) & Yes (25), sometimes (5), other (2) \\
\hline
\end{tabular}

* In addition to high-dose steroids. \# Discontinuation of antimalarials in patients with stable SLE who have been taking the medication for a prolonged period and continue in remission. ${ }^{\dagger}$ Adjustment of immunosuppression to facilitate steroid taper and discontinuation in a stable SLE patient with low disease activity requiring $<10 \mathrm{mg}$ oral daily steroid. ${ }^{*}$ Discontinuation of immunosuppression in patient with SLE who achieved and maintained remission while taking steroid-sparing agent for a prolonged period. SLE: systemic lupus erythematosus; MMF: mycophenolate mofetil; RTX: rituximab; HCQ: hydroxychloroquine; AZA: azathioprine; CYC: cyclophosphamide; LEF: leflunomide; ABA: abatacept; NSAID: nonsteroidal antiinflammatory drug; MTX: methotrexate; SSZ: sulfasalazine; TNF: tumor necrosis factor; IV: intravenous.

indicated they used these drugs in up to $80 \%$ of their patients. The majority $(79 \%)$ reported not discontinuing antimalarials in patients with stable SLE who had taken medication for a long time (Table 3). Antimalarials were the most commonly used agent for active SLE skin disease (96\%). CYC was the first-line agent suggested for central nervous system SLE $(82 \%)$ and pulmonary hemorrhage (92\%), respectively. About one-quarter of responders stated that they used longterm low-dose prednisone in about $6 \%$ to $10 \%$ of their patients. Reports of discontinuing immunosuppression in the patient with stable SLE varied considerably. When we compared academic and nonacademic rheumatologists in the use and discontinuation of antimalarials and use of longterm low-dose prednisone, we were unable to demonstrate definite differences (data not shown).

Only 48 responders had used belimumab in SLE and of these, half $(52 \%)$ used it for the treatment of arthritis; responders also used it for cutaneous SLE (43\%), serositis $(25 \%)$, and cytopenias $(17 \%)$. Belimumab use was reported less often $(<10 \%$ of responders) for other manifestations including vasculitis, interstitial lung disease, and gastrointestinal manifestations. Responders reported that they used
RTX mostly in the treatment of cytopenias (36\%), followed closely by arthritis (35\%) and vasculitis (32\%).

Most respondents indicated that patients taking antimalarials were referred to ophthalmology, with the majority (71\%) reporting screening every 6-12 months (Table 4$)$. The majority of responders $(55 \%)$ indicated that the percentage of patients requiring discontinuation of antimalarials was $<1 \%$.

Pregnancy and reproductive issues in SLE. Nearly half (46\%) of responders to this section did not believe that estrogen-containing oral contraceptives (OC) increased flare risk in SLE (Table 5). For patients without antiphospholipid syndrome (APS), low-dose estrogen OC was "sometimes" used by $62 \%$ of responders, whereas moderate or higher doses were rarely used. Other methods of contraception [progesterone/intrauterine device (IUD)] were sometimes used, while abstinence or the rhythm method were never used by most responders. In contrast, for SLE patients with APS, the majority would never use any formulation of estrogen but would sometimes (53\%) use the IUD for this group of patients.

In preconception counseling, a significant majority (85\%)

$$
\text { Personal non-commercial use only. The Journal of Rheumatology Copyright (c) 2018. All rights reserved. }
$$


Table 4. Antimalarial ophthalmological toxicity screening $(\mathrm{n}=147$ responders).

\begin{tabular}{lll}
\hline Questionnaire Items & Mode (\% responders) & Commonly Repeated Strategies (\% responders) \\
\hline Type of screening for patients with SLE taking antimalarials & Ophthalmology referral (77) & $\begin{array}{l}\text { Visual field testing (45), optometry referral (23), other (16), } \\
\text { electroretinogram (5) }\end{array}$ \\
$\begin{array}{l}\text { Frequency of ophthalmology/optometry checks for patients } \\
\text { with SLE taking antimalarials }\end{array}$ & Every 6-12 months (71) & $\begin{array}{l}\text { Every 13-24 months (26), determined by ophthalmologist/ } \\
\text { optometrist (20), dictated by type of antimalarial (5), every } \\
\text { 25 to 36 months (2), never (1) }\end{array}$ \\
$\begin{array}{l}\text { \% patients who discontinued antimalarial because of } \\
\text { related retinopathy }\end{array}$ & $0-1 \%$ of patients (55) & $\begin{array}{l}2-5 \% \text { patients (33), 6-10\% patients (9), other (2), 11-20\% } \\
\text { patients (1), 20\% patients (0) }\end{array}$ \\
\hline
\end{tabular}

SLE: systemic lupus erythematosus.

Table 5. Pregnancy and SLE $(\mathrm{n}=130$ responders*).

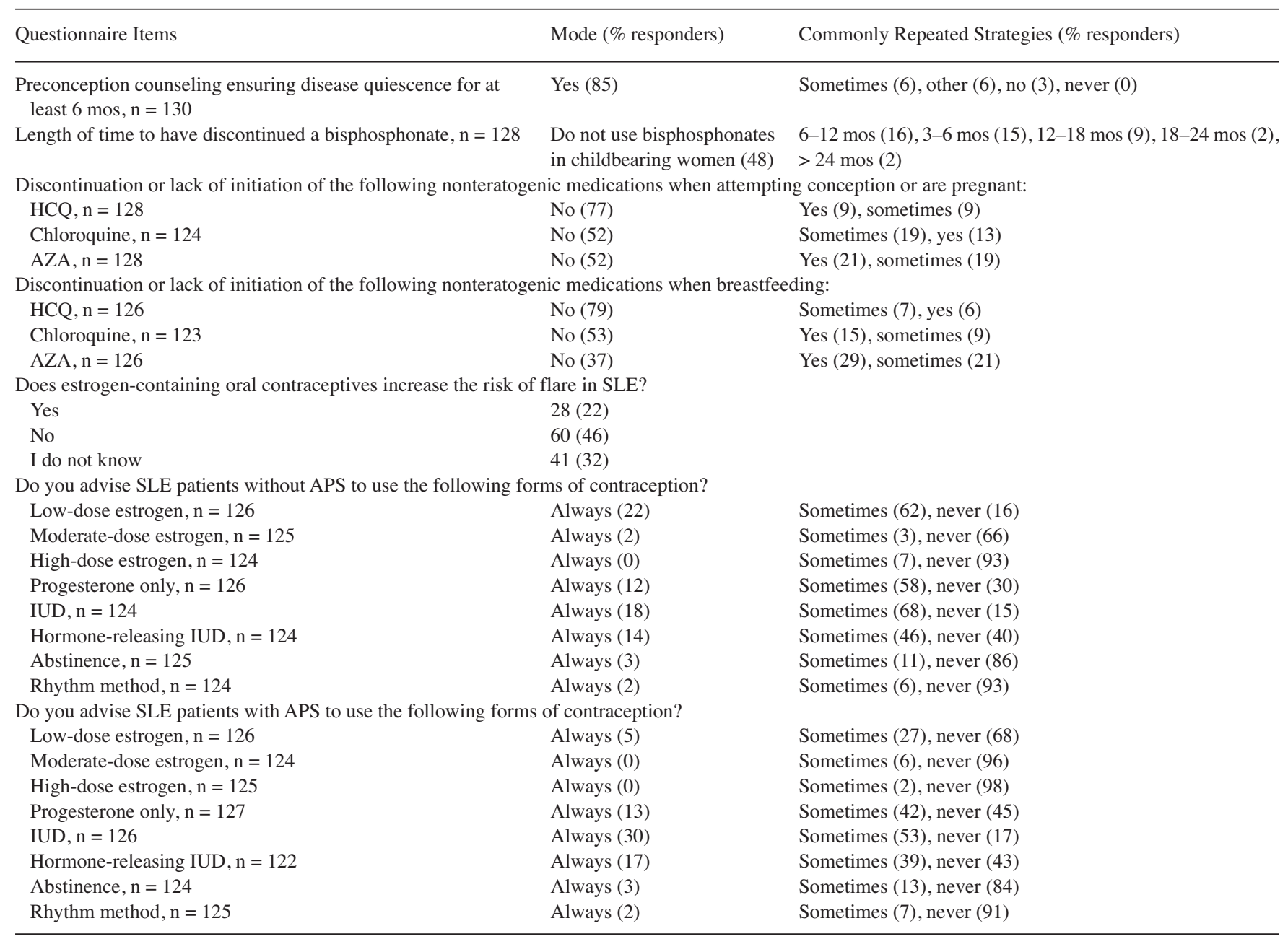

* The $\mathrm{n}$ is provided per question because responders were given the option to skip questions that were not applicable to their practice. SLE: systemic lupus erythematosus; HCQ: hydroxychloroquine; AZA: azathioprine; APS: antiphospholipid antibody syndrome; IUD: intrauterine device.

of responders recommended disease quiescence for at least 6 months prior to conception attempts (Table 5). When asked whether the rheumatologist commonly stops particular nonteratogenic medications, chloroquine or AZA were more likely to be discontinued during pregnancy and breastfeeding than HCQ (Table 5). Frequency of visits for the pregnant patient with stable SLE varied, with the greatest proportion of responders $(41 \%)$ recommending 1 visit per trimester.

Comorbidities in SLE. The most commonly measured traditional cardiovascular $(\mathrm{CV})$ risk factors by the majority of 
respondents included high blood pressure (94\%) and weight concerns (74\%), whereas other specific CV risk scores were regularly assessed by less than $10 \%$ of responders (Table 6). The most common reasons for infrequent $\mathrm{CV}$ risk factor assessment included the belief that the responsibility lay with the primary care physician (46\%) and/or rheumatologists were too busy managing other SLE concerns (34\%). Slightly over $50 \%$ of responders reported reviewing and/or recommending vaccinations either prior to or during regular followup. Many (56\%) did not report withholding the vaccination during immunosuppression to ensure seroconversion. Nearly all reported using calcium and vitamin D for patients with SLE taking steroids for prolonged periods at any dose (e.g., > 1 month), whereas bisphosphonate use was routine for $50 \%$ of respondents in this situation (Table 6).

Optimizing patient care. Most responders (80\%) agreed that a dedicated multidisciplinary care team including many different types of healthcare workers (e.g., rheumatologist, nurse, clinical psychologist, etc.) would improve the care of their patients with SLE and just over half (53\%) said that the family physician played a pivotal role in optimal SLE care. Other sources of support and information (e.g., Internet or a Lupus Health Passport) were deemed potentially useful by over half $(56 \%)$ of responders. Eighty-five percent of responders closely collaborated with other specialists and the majority (70\%) acknowledged the usefulness of combined specialty clinics for SLE management. Tools such as EMR and "health passports" were not widespread in the practices surveyed (43\%), with only 61 respondents (34\%) reporting that they used EMR in their practice to assess patients with SLE.

\section{DISCUSSION}

Significant heterogeneity exists when diagnosing, monitoring, and treating patients with SLE across Canada. This potentially has great implications on disease and patient-specific outcomes.

The use of the ACR Classification Criteria as diagnostic criteria by a significant number of responders implies that some patients with SLE might be missed by these criteria. More recent criteria for SLE classification have been published, including the 2012 SLICC Classification Criteria for SLE, but uptake has been uneven ${ }^{13}$. Few respondents reported using SLE-specific disease activity and damage scores for the monitoring of patients. Reasons may include the lack of familiarity with these measures and their perceived or real complexity (e.g., British Isles Lupus Assessment Group ${ }^{14}$ ). At the time of the survey, performance of these measures was not tied into medication reimbursement as it may be with other rheumatic diseases. The movement toward treat-to-target strategies in SLE (similar to that in diseases such as rheumatoid arthritis) suggests that specific tools evaluating disease activity may become more familiar to SLE caregivers ${ }^{15}$. Presently there is great variability regarding what laboratory tests are done (and how often) in Canadian patients with SLE. Regarding the 1999 ACR recommendations that urine protein should be monitored in patients with SLE at routine followup visits ${ }^{16}$, the vast majority of our respondents indicated that they follow patients with urinalyses, though less than half routinely requested urine protein levels.

A recent study surveying 283 patients with SLE and 86 rheumatologists in the United States identified unnecessary

Table 6. Comorbidities in SLE.

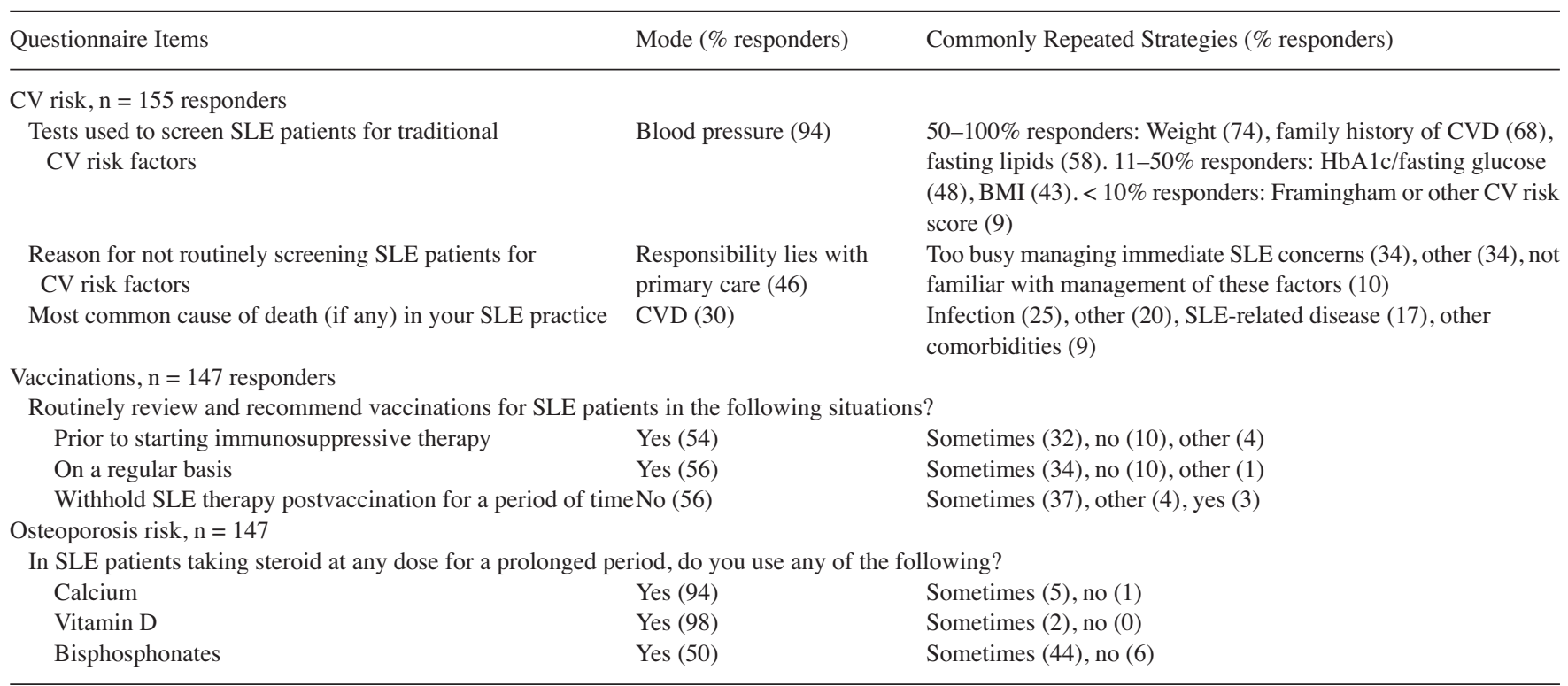

SLE: systemic lupus erythematosus; CV: cardiovascular; CVD: CV disease; BMI: body mass index.

Personal non-commercial use only. The Journal of Rheumatology Copyright $\odot$ 2018. All rights reserved. 
laboratory investigations in routine practice for patients at every visit ${ }^{17}$. Significant differences were noted between academic and private practice rheumatologists, and the authors concluded that such variations raise healthcare costs and reduce the equity of care across the country ${ }^{18,19}$. Our study was similar to this study in revealing the overuse of unhelpful tests such as ANA for ongoing disease monitoring, which wastes resources and provides no valuable information in disease assessment over time. Moreover, we found differences between academic and nonacademic sites in monitoring disease activity and damage over time, which suggests that standardization across different sites with simpler, feasible tools would be helpful.

The diversity of responses regarding the pharmacotherapy of SLE further supports the need to provide guidance to healthcare providers in the form of recommendations. The relatively low use of biologics was not surprising owing to limited availability of these medications for the treatment of SLE in Canada.

Antimalarials were reported as widely used by rheumatologists. Over $60 \%$ of respondents indicated that $80-100 \%$ of their patients were taking these drugs, while another $25 \%$ indicated they used these drugs in up to $80 \%$ of their patients. Many considered reducing or stopping various agents (including antimalarials) in stable, remitted patients despite increased risk of flare. Our responses suggested that some patients with SLE are taking low-dose prednisone in the long term. The longterm morbidity and mortality secondary to high-dose glucocorticoids is well known ${ }^{20,21}$, although the effects of very low-dose longterm steroids is less established.

In contrast to disease assessments over time, no statistically significant difference between rheumatologists practicing at academic versus nonacademic centers was found related to the use and discontinuation of antimalarials and indefinite use of low-dose glucocorticoids over time. These results may reflect specific site differences, variations in the level of experience, and concerns about the toxicities of antimalarials.

This survey was conducted in 2012 when access to belimumab, RTX, and MMF was limited in many regions of Canada. While access to MMF has improved overall, the access for biologics in SLE is still limited in several provinces, suggesting that lobbying for better access may be in order.

Differences in managing potential medication toxicities (e.g., ophthalmology screening for antimalarials) require clarification. The greater discontinuation of chloroquine versus HCQ in pregnancy may reflect lingering concerns for some rheumatologists of more chloroquine-related retinal abnormalities in those offspring exposed in pregnancy, despite a metaanalysis suggesting that the risk is not significant $^{22}$. Moreover, the discontinuation of antimalarials and AZA in pregnancy may increase the risk of flare for this subset of patients ${ }^{23,24}$. Variability in contraception use for
SLE patients with or without APS demonstrates uncertainty in managing these patients. Answers to the oral contraceptive questions might have changed since the survey was administered because of more recent evidence of impairment of efficacy of oral contraceptives with concomitant mycophenolate use ${ }^{25}$

Despite $30 \%$ of respondents identifying CV disease (CVD) as the most common cause of death, little consensus was found over the primary manager of $\mathrm{CV}$ problems. This may suggest that formal definition of where the responsibility lies for CVD screening may help optimize SLE care. However, the roles of family doctors versus specialists may vary significantly across regions and jurisdictions (owing to differences in the supply of physicians) and may also need to be tailored to the preferences and needs of the patient. Great variability in vaccinations and when they are delivered was noted. Despite use of calcium and vitamin D, use of bisphosphonates in patients with prolonged steroid exposure was not universal. Reasons may include that many patients with SLE are of reproductive age, and bisphosphonate use in this age group is often avoided because of concerns that the drug may later cause problems in offspring ${ }^{26}$. Renal dysfunction may also make use of bisphosphonates difficult. Ultimately, the variations noted in the management of comorbidities including CVD and osteoporosis risk among Canadian rheumatologists suggest the need to clarify and define the roles of rheumatologists and primary care physicians in these important aspects of SLE care.

Although this study was pilot-tested with a panel of rheumatology experts from community and academic practices, limitations were unavoidable. Using a multiple-choice format with prespecified response options may have excluded some approaches practiced by CRA members. The "other" option, along with an open-ended "comment" section at the end of the survey, attempted to increase sensitivity of the results. Responses were not mandatory, resulting in certain sections having fewer responses, especially the pregnancy section. Possible reasons for these fewer responses included discomfort or lack of clarity by responders in managing pregnant patients with SLE. The survey sample of CRA members answering the e-mail link was regarded as representing the current body of rheumatologists in Canada. Inclusion of CaNIOS members was meant to ensure that other important SLE caregivers (e.g., immunologists) who might not be CRA members were included. Demographic distributions were comparable to those of the 2012 CRA membership $(n=494)$ regarding sex and provincial distribution. As an important potential limitation, individual practice approaches may have changed since 2012. This may be especially true in the increased uptake of EMR over that past 6 years, although many sites do not integrate SLE-disease activity or damage indices even now despite using EMR systems (personal communication with members of CRA).

Personal non-commercial use only. The Journal of Rheumatology Copyright $\odot$ 2018. All rights reserved. 
This survey demonstrates significant practice variations in the diagnosis, monitoring, and treatment of SLE in Canada and raises concerns that optimal care was not always available to patients with SLE in Canada. The results support the mission of the Canadian SLE Working Group in conjunction with the CRA to evaluate these variations in depth, and to formulate recommendations for the assessment and monitoring of SLE in Canada. These recommendations have used GRADE methodology, which incorporates best available evidence with patient preferences, cost considerations, and benefits and harms. These recommendations from the patient and physician perspectives will be evaluated to ultimately strive for decreased disparity and improvement in the quality of life of patients in Canada with SLE.

\section{ONLINE SUPPLEMENT}

Supplementary material accompanies the online version of this article.

\section{REFERENCES}

1. Wallace DJ. New European recommendations (European League Against Rheumatism 2008) for the management of lupus erythematosus: American perspective. Pol Arch Med Wewn 2008;118:402-3.

2. Mosca M, Tani C, Aringer M, Bombardieri S, Boumpas D, Brey R, et al. European League Against Rheumatism recommendations for monitoring patients with systemic lupus erythematosus in clinical practice and in observational studies. Ann Rheum Dis 2010;69:1269-74.

3. Groot N, Graeff N, Avcin T, Bader-Meunier B, Brogan P, Dolezalova P, et al. European evidence-based recommendations for diagnosis and treatment of childhood-onset systemic lupus erythematosus: the SHARE initiative. Ann Rheum Dis 2017;76:1788-96.

4. American College of Rheumatology Ad Hoc Committee on Systemic Lupus Erythematosus Response Criteria. The American College of Rheumatology response criteria for systemic lupus erythematosus clinical trials: measures of overall disease activity. Arthritis Rheum 2004;50:3418-26.

5. Hanly JG. ACR classification criteria for systemic lupus erythematosus: limitations and revisions to neuropsychiatric variables. Lupus 2004;13:861-4.

6. Stephenson JL, Shipman AR. The Systemic Lupus International Collaborating Clinics criteria have replaced the American College of Rheumatology guidelines for the diagnosis of systemic lupus erythematosus. Clin Exp Dermatol 2014;39:431-2.

7. Bernatsky S, Joseph L, Pineau CA, Tamblyn R, Feldman DE, Clarke AE. A population-based assessment of systemic lupus erythematosus incidence and prevalence-results and implications of using administrative data for epidemiological studies. Rheumatology 2007;46:1814-8.

8. Carter EE, Barr SG, Clarke AE. The global burden of SLE: prevalence, health disparities and socioeconomic impact. Nat Rev Rheumatol 2016;12:605-20.

9. Tan EM, Cohen AS, Fries JF, Masi AT, McShane DJ, Rothfield NF, et al. The 1982 revised criteria for the classification of systemic lupus erythematosus. Arthritis Rheum 1982;25:1271-7.
10. Hochberg MC. Updating the American College of Rheumatology revised criteria for the classification of systemic lupus erythematosus. Arthritis Rheum 1997;40:1725.

11. Bombardier C, Gladman DD, Urowitz MB, Caron D, Chang CH. Derivation of the SLEDAI. A disease activity index for lupus patients. The Committee on Prognosis Studies in SLE. Arthritis Rheum 1992;35:630-40.

12. Gladman D, Ginzler E, Goldsmith C, Fortin P, Liang M, Urowitz M, et al. The development and initial validation of the Systemic Lupus International Collaborating Clinics/American College of Rheumatology damage index for systemic lupus erythematosus. Arthritis Rheum 1996;39:363-9.

13. Petri M, Orbai AM, Alarcón GS, Gordon C, Merrill JT, Fortin PR, et al. Derivation and validation of Systemic Lupus International Collaborating Clinics Classification Criteria for Systemic Lupus Erythematosus. Arthritis Rheum 2012;64:2677-86.

14. Symmons DP, Coppock JS, Bacon PA, Bresnihan B, Isenberg DA, Maddison P, et al. Development and assessment of a computerized index of clinical disease activity in systemic lupus erythematosus. Members of the British Isles Lupus Assessment Group (BILAG). Q J Med 1988;69:927-37.

15. van Vollenhoven RF, Mosca M, Bertsias G, Isenberg D, Kuhn A, Lerstrom K, et al. Treat-to-target in systemic lupus erythematosus: recommendations from an international task force. Ann Rheum Dis 2014;73:958-67.

16. Guidelines for referral and management of systemic lupus erythematosus in adults. American College of Rheumatology Ad Hoc Committee on Systemic Lupus Erythematosus Guidelines. Arthritis Rheum 1999;42:1785-96.

17. Kugasia A, Sehgal N, Dollear M, Sequeria W, Bloack JA, Jolly M. Practice patterns in longitudinal lupus care provision: patient and physician perspectives. Lupus 2017;26:1556-61.

18. Wennberg JE. Unwarranted variations in healthcare delivery: implications for academic medical centres. BMJ 2002;325:961-4.

19. Gauld R, Horwitt J, Williams S, Cohen AB. What strategies do US hospitals employ to reduce unwarranted clinical practice variations? Am J Med Qual 2011;26:120-6.

20. Thamer M, Hernan MA, Zhang Y, Cotter D, Petri M. Prednisone, lupus activity, and permanent organ damage. J Rheumatol 2009;36:560-4

21. Zahr ZA, Fang H, Magder LS, Petri M. Predictors of corticosteroid tapering in SLE patients: the Hopkins Lupus Cohort. Lupus 2013;22:697-701.

22. Osadchy A, Ratnapalan T, Koren G. Ocular toxicity in children exposed in utero to antimalarial drugs: review of the literature. J Rheumatol 2011:38:2504-8.

23. Canadian Hydroxychloroquine Study Group. A randomized study of the effect of withdrawing hydroxychloroquine sulfate in systemic lupus erythematosus. N Engl J Med 1991;324:150-4.

24. Tsakonas E, Joseph L, Esdaile JM, Choquette D, Senecal JL, Cividino A, et al. A long-term study of hydroxychloroquine withdrawal on exacerbations in systemic lupus erythematosus. The Canadian Hydroxychloroquine Study Group. Lupus 1998;7:80-5.

25. Roche Pharmaceuticals. CellCept (mycophenolate mofetil) US prescribing information. [Internet. Accessed June 27, 2018.] Available from: www.accessdata.fda.gov/drugsatfda_docs/label/ 2009/050722s021,050723s019,050758s019,050759s024lbl.pdf

26. Kovacs CS, Ralston SH. Presentation and management of osteoporosis presenting in association with pregnancy or lactation. Osteoporos Int 2015;26:2223-41. 